\title{
Electronic Medical Records in the American Health System: challenges and lessons learned
}

\author{
Registros Eletrônicos de Saúde no Sistema de Saúde norte- \\ americano: desafios e lições aprendidas
}

Robert S. Janett (https://orcid.org/0000-0002-8458-7296) ${ }^{1}$

Peter Pano Yeracaris (https://orcid.org/0000-0002-4017-3171) ${ }^{2}$

${ }^{1}$ Cambridge Health Alliance. 237 Hampshire Street. 02139 Cambridge Massachusetts USA. robjanett@nefeshhealth.com

${ }^{2}$ Care Transformation Collaborative Rhode Island. Providence Rhode Island USA.

\begin{abstract}
Electronic medical records have been touted as a solution to many of the shortcomings of health care systems. The aim of this essay is to review pertinent literature and present examples and recommendations from several decades of experience in the use of medical records in primary health care, in ways that can help primary care doctors to organize their work processes to improve patient care. Considerable problems have been noted to result from a lack of interoperability and standardization of interfaces among these systems, impairing the effective collaboration and information exchange in the care of complex patients. It is extremely important that regional and national health policies be established to assure standardization and interoperability of systems. Lack of interoperability contributes to the fragmentation of the information environment. The electronic medical record (EMR) is a disruptive technology that can revolutionize the way we care for patients. The EMR has been shown to improve quality and reliability in the delivery of healthcare services when appropriately implemented. Careful attention to the impact of the EMR on clinical workflows, in order to take full advantage of the potential of the EMR to improve patient care, is the key lesson from our experience in the deployment and use of these systems.
\end{abstract}

Key words Electronic medical records, Primary health care
Resumo Os registros médicos eletrônicos (RME) têm sido apontados como uma solução para muitas das deficiências dos sistemas de saúde. O objetivo deste ensaio é revisar a literatura pertinente e apresentar exemplos e recomendações de várias décadas de experiência no uso de registros médicos na atenção primária à saúde, de maneira a ajudá-los na organização de seus processos de trabalho para melhorar o atendimento ao paciente. Observou-se que problemas consideráveis resultam da falta de interoperabilidade e padronização de interfaces entre esses sistemas, prejudicando a colaboração efetiva e a troca de informações no atendimento a pacientes complexos. É extremamente importante que politicas regionais e nacionais de saúde sejam estabelecidas para garantir a padronização e interoperabilidade dos sistemas. A falta de interoperabilidade contribui para a fragmentação do ambiente de informações. O prontuário eletrônico (RME) é uma tecnologia disruptiva que pode revolucionar a maneira como cuidamos dos pacientes. Foi demonstrado que o RME melhora a qualidade e a confiabilidade na prestação de serviços de saúde quando implementada adequadamente. Uma atenção cuidadosa ao impacto do RME nos fluxos de trabalho clínicos, a fim de aproveitar ao máximo o potencial do RME para melhorar o atendimento ao paciente, é a principal lição de nossa experiência na implantação e uso desses sistemas.

Palavras-chave Registros eletrônicos de saúde, Atenção primária à saúde 


\section{Introduction}

Electronic medical records have been touted as a solution to many of the shortcomings of health care systems $\mathrm{s}^{1-3}$. Others have criticized the move toward the electronic medical record (EMR) as a threat to the physician patient relationship, to patient privacy, and as an additional administrative burden to the health system contributing to physician burn-out ${ }^{4,5}$. A modern EMR is not simply a digitized paper chart. Rather, it is a digital application that can actively interact with providers and patients and is composed of a series of data fields that lend themselves to analysis, processing, and reporting to support communication, appropriate clinical interventions, quality improvement, and patient safety.

As authors of this article, we both have practiced medicine using paper charts and were present for the painful transition from paper to electronic records. We are primary care physicians and have been users and implementers of electronic health records in public and private health systems, locally and regionally in the northeast United States. The first section of this paper will describe the evidence for the benefits and drawbacks of electronic medical records. In the second section we will then describe, from the literature and our experience, some of the ways that electronic records can be optimally used to support better health care delivery for individual patients while simultaneously improving health care delivery to populations.

There is no perfect electronic medical record system, but there are features of systems that have been shown to improve reliability, quality, and efficiency over time. There is no better tool than an EMR to integrate patient care among members of the care team at a specific facility (horizontal integration), and among providers and various facilities at the primary, secondary, and tertiary levels of care (vertical integration). A high functioning EMR helps reduce fragmentation in the care delivery system and this improves quality and efficiency by reducing gaps in care. An EMR can offer reminders of important interventions that are needed at the time of an office visit and can track and flag patients who do not present themselves for follow up care in an appropriate timeframe.

At the same time, EMR systems are costly to implement and to maintain, and can also be challenging because an EMR impacts virtually all of the workflows and care processes in a clinical environment.
The EMR is particularly useful in primary care settings, especially because primary care is the locus of most care coordination activities that occur in health systems. Comprehensive integrated primary care ${ }^{6-8}$ is perhaps the most significant contributor to reform of the American health system. Electronic records are an essential component of this evolving care model and are designed to support many of the unique features of robust primary care, as we will describe in detail. Key features of this comprehensive care model $^{9}$ include empanelment of patients with specific provider teams, advanced access to appointments, team-based multidisciplinary care, shared responsibility among team members for providing evidence-based patient interventions in a reliable way, shared access to clinical information across members of the care team, electronic communication with patients, checklists to support the closure of gaps in care at the time of the office visit, and active outreach to patients who do not visit the office but who are identified to have gaps in care. Moreover, coordination of complex care with specialists and hospitals involves shared access to clinical information and secure channels of communication.

\section{Evidence for the Impact of the EMR on Medical Practice}

There is ample evidence from the global literature on the impact of the EMR on clinical practice. A systematic review ${ }^{10}$ showed that adoption of an EMR improved structural and process components in primary care, with less clear evidence of the EMR's impact on outcomes. A 2006 study on pediatric practices ${ }^{11}$ showed that larger practices were more likely to adopt an EMR than smaller practices because of cost concerns, and the lack of decision support features in EMRs of that era limited the impact on quality of care. Kaiser Permanente, the largest private integrated health system in the United States, showed that implementation of the EMR significantly reduced demand for primary care and specialist office visits, with a concomitant increase in e-mail and telephonic communications between patients and providers, resulting in operational efficiencies while offering more patient-centric access to providers ${ }^{12,13}$.

Costs of implementing an EMR have been studied and analyzed. Costs are classified into two broad categories: the direct economic cost of the system with associated expenses, and the costs in person-hours of implementation and 
use of the EMR. Implementation time is significant, as one physician network in Texas showed ${ }^{14}$. A practice-based information technology team required 611 hours on average to prepare and deploy a new EMR system. End user physicians and other clinical team members required 134 hours, on average, per physician to prepare to use the system in clinical encounters. The financial cost to this group was estimated to be $\$ 162,000$ for a five-physician practice, with $\$ 85,000$ in maintenance expenses during the first year. Another study ${ }^{15}$ showed that the economic benefit of an EMR was $308.6 \%$ of the annual cost of the system. A time motion study in five practices showed that the overall time spent face-to-face with patients after implementation of an EMR decreased by about 30 seconds ${ }^{16}$.

Primary care providers vary in their attitudes to the adoption of an EMR. A systematic review of the world literature ${ }^{17}$ demonstrated that younger, more computer literate primary care physicians who are based in larger practices view the EMR positively, compared to older physicians who are less skilled in the use of technology and who are based in solo practices. Factors such as training, policies and procedures, and financial incentives can be used to favorably influence physician attitudes toward the EMR. Another study from the U.S. Veterans Administration ${ }^{18}$ has similar findings.

The impact of the EMR on the physician-patient relationship has been extensively studied. Capture of biomedical information improved while collection of emotional and psycho-social information was felt to be compromised. At the same time, patient access to the information in the EMR and reliably secure messaging functions increased patient engagement, empowerment, and self-management ${ }^{19}$. Physician-patient eye contact is a critical element of communication and a study showed that the EMR alters physician and patient interactions with regard to gaze $\mathrm{e}^{20}$. Impact on patient satisfaction with the use of an EMR in the examination room was found to neutral to positive but the evidence for this impact was weak ${ }^{21,22}$. One systematic review ${ }^{21}$ revealed communication behaviors in the examination room that were potentially beneficial (facilitating questions) and others that were potentially negative (low rates of screen sharing, interrupted speech). Screen sharing with the patient is one strategy that has been used to mitigate some of the barriers. Another review ${ }^{23}$ found positive impact on information exchange with a negative impact on patient-centeredness, noting that the characteristics of some physicians (behavioral style and computer skills) overcame the negative influences of the EMR on patient-doctor communication.

A systematic review of the literature on the use of EMRs to support population health ${ }^{24}$ identified factors that facilitate and others that are barriers to adoption of the technology for this purpose. Of twenty-six factors, $63 \%$ were facilitators and $37 \%$ were barriers. Factors that facilitate population health include improved productivity and efficiency, improved quality, data management, surveillance, and preventive care. Factors that were deemed barriers to population health management include missing data, lack of standards for interoperability of different EMR systems, loss of productivity, and overly complex technology. The authors concluded that wider adoption of EMRs with more comprehensive standards for interoperability among systems will improve the capacity to conduct surveillance and disease management and prevention.

A meta-analysis on the impact of the EMR on healthcare quality ${ }^{25}$ found a $22.4 \%$ reduction in documentation time, higher adherence to clinical guidelines, and a lower number of medication errors. There was a striking reduction in the number of adverse drug events. A study of the pharmaceutical component of safety alert features of EMRs in the United States ${ }^{26}$ showed statistically significant reduction in medication errors in patients with chronic kidney disease, reduction in dispensing of potentially teratogenic drugs to pregnant women, reduction of inappropriate prescribing for geriatric patients, reduction of co-dispensing of interacting drugs, and a reduction of adverse drug events related to hyperkalemia. Care processes are clearly impacted by adoption of an EMR. A study of a primary care group ${ }^{27}$ showed marked improvement of performance on quality metrics after adoption of an EMR, a near doubling of the rate of obtaining mammograms, varicella immunizations, and glycosylated hemoglobin testing and influenza immunization in patients with diabetes.

The EMR's impact on a variety of health improvement interventions has been systematically studied. Automated reminders and prompts to administer the human papilloma virus vaccine to appropriate patients performed significantly better compared with EMRs that did not include these features ${ }^{28}$. Changes in systems of care along with the use of an EMR had a salutary effect on tobacco screening and treatment rates in public hospitals serving low income patients ${ }^{29}$, with a 
significant reduction in tobacco use among patients at these hospitals. Advance care planning to ensure that care is concordant with patients wishes was positively impacted by the use of tools including documentation templates, automated prompts and electronic order sets within the $\mathrm{EMR}^{30}$. This systematic review showed more frequent documentation of advance care planning conversations, placement of code status orders, and improvement in advance care planning outcomes.

Management of diabetes mellitus using an EMR has been carefully evaluated. Adherence to diabetes care standards improved 35.1 percentage points and achievement of composite standards for diabetes outcomes improved 15.2 percentage points in a large study of 27,207 adults seen at 46 practices $^{31}$. Thirty-eight percent of these patients were seen at 'safety net' facilities that treat predominantly low-income individuals. The availability of a patient portal to facilitate secure electronic messaging between providers and patients $^{32}$ was associated with a significant improvement in patients' glycohemoglobin levels. A meta-synthesis of articles on diabetes care and management using an $\mathrm{EMR}^{33}$ showed that diabetes patients benefit most from decision support tools to notify physicians of drug interactions, communication tools to keep patients engaged in treatment and informed of their progress, as well as reporting and tracking tools to inform providers of gaps in care and their performance in closing those gaps.

In any discussion of the EMR, it is important to elucidate some of the significant drawbacks and potential risks in adopting an EMR system. As noted, implementation and maintenance costs can be high. Disruption of established workflows and at least a transient initial decrease in patient visit volumes and revenue are common concerns. Electronic systems also raise the specter of potential violations of patient confidentiality and breaches of private personal information ${ }^{34}$. The failure of various EMR systems to standardize protocols for interoperability can impair appropriate information sharing among providers caring for a patient. Environments with multiple different electronic medical record systems or with a mixture of electronic and paper systems present impediments to the EMR's potential to improve collaboration and care coordination through vertical integration ${ }^{4}$. In these circumstances, practices often revert to scanning of printed documents, degrading the power of an EMR to search and compare clinical data that would otherwise be entered into specific fields. National and regional policies are required to establish standards for EMR interoperability.

Moreover, the proprietary nature of most EMR systems can result in a lack of transparency that can hide coding defects within the EMR systems themselves, which can cause systematic errors in reportable fields and other important elements. Specific errors related to usability have also been documented. Complex user interfaces make it more difficult to navigate the EMR and can increase the likelihood of erroneous orders for medications, testing, and other interventions $^{35}$. Patient safety issues in medication management have been noted when weights are entered in pounds rather than kilograms, resulting in incorrect dosing of weight-based medicines ${ }^{34}$.

\section{Key Features and Functions of Electronic Medical Records that Support an Integrated Care Model}

Our experience from several decades of work are presented to illustrate ways in which the EMR offers features and functions that support and improve care, making it more reliable and safer for patients.

\section{Quality of care}

Improving care quality is a challenge in all health systems. Quality improvement is a systematic approach to improving care using metrics to inform results. Quality improvement methods are applied to many components of care, including provider access and availability, efficiency of patient flow, patient satisfaction, chronic disease management, provision of preventive services, effective use of acute care services, transitions of care, and care coordination, among others. As we discussed in Section I, the use of an EMR has been shown to improve performance on a variety of quality indicators, compared to practices that use paper records. But quality improvement requires more than an electronic record. More effective and reliable systems of care and workflows, guided by information contained in the electronic record, are required for sustainable performance improvement ${ }^{36,37}$. With established standards of care and clinical protocols encoded into the system software, reminders, checklists, registries, patient outreach and engagement, and reporting, the EMR supports the clinical team's efforts to optimize the structure, process, efficiency, effectiveness, and outcome of care. Since 
performance measurement is an essential element of quality improvement work, an essential contribution of an EMR can be to streamline the measurement and analysis of data on clinical performance metrics, assuming that the system is properly configured, data fields are accurately completed, and that the software application is sophisticated enough to support the measurement and reporting process.

This is an example of ways in which an EMR and the associated changes in the care model can improve management of patients with type II diabetes. First, a nationally recognized care protocol is endorsed by the provider organization, is accepted as a care standard, and is encoded into the EMR software. The EMR is organized to detect patients who are overdue for specific testing such as glycohemoglobin, nephropathy screening, or retina examination or who have other care interventions that are not compliant with the care protocol. The EMR can generate a check list of these gaps in care on any patient on any given day. Patients who are scheduled to be seen in the office can be offered the missing services regardless of the reason for the visit. And patients who are not scheduled to be seen can be reviewed in a diabetes registry. Those with gaps in care who do not have appointments can be contacted by e-mail, letter, or telephone as part of the active outreach process. These workflows, guided by EMR based information, reliably improve performance on diabetes care measures. By embedding quality improvement work in the daily care activities, performance improvement is sustained over time (Chart 1).

\section{Support for the Team-based Care Model}

Team-based care is an essential component of comprehensive integrated primary care and a well-functioning EMR can be strategically deployed to support the essential functions of the multidisciplinary team ${ }^{9,38,39}$. High functioning primary care practices have teams composed of physicians, advanced practice nurses, physician assistants, clinical pharmacists, nurse care managers (for coordination of chronic disease care and for patient education), behavioral health specialists, social workers, nutritionists, medical assistants, nurses, receptionists and population health managers. This care model has been shown to improve quality of care and to increase the capacity to care for more patients, while simultaneously decreasing physician workload. Ideal staffing requires the deployment of 2 or
2.5 full-time-equivalent well-trained medical assistants per full time physician ${ }^{38}$. An important task of the medical assistant in these settings is to assist with record keeping of the clinical encounter as a "scribe", carefully documenting the clinical encounter in the EMR, in real time, as the physician cares for the patient ${ }^{38}$. "Scribes" have been shown to document clinical notes that are as accurate, or more accurate, than those of a physician $^{40}$.

With appropriate guidance and training, medical assistants are able to perform a number of routine functions such as cancer screening, provision of preventive services, scheduling appointments with specialists, obtaining protocol-driven lab testing, among others. These clinical processes and pathways make care more reliable and result in more efficient and effective patient visits. With routine interventions managed by an information-system driven protocol that guides the activities of non-physician team members, physicians are able to better focus on care activities that depend on their specialized knowledge, training and professional expertise to establish and strengthen the patient-physician relationship ${ }^{38,41}$ and attend to the subtleties of formulating difficult diagnoses, engaging in shared decision making, and attending to the patient's psycho-social needs (Chart 2).

\section{The EMR as a tool to facilitate communication}

A high functioning EMR will support effective and efficient communication between patients and health care providers, support horizontal integration within the clinic, and support vertical integration between primary care, specialists, hospitals, laboratories and imaging centers.

\section{With Patients}

Patient portals support bidirectional communication, offering patients easier ways to interact with providers without the need for a face-to-face office visit or telephone call. While younger patients may be accustomed to e-mail and text messaging, electronic messaging can be more challenging to older patients. But experience is showing us that even older patients with chronic disease are starting to use patient portals and are enjoying enhanced access to their provider teams. The goals of an effective patient portal include; fostering better patient-physician relationships, improving clinical outcomes, and 
Chart 1. Examples of EMR and Workflows to Support Quality Improvement Activities at the Point of Care of Patients with Diabetes Mellitus.

\begin{tabular}{|c|c|c|c|}
\hline $\begin{array}{c}\text { Quality } \\
\text { Improvement } \\
\text { Intervention }\end{array}$ & $\begin{array}{c}\text { EMR } \\
\text { Function }\end{array}$ & Workflow & Example \\
\hline $\begin{array}{l}\text { Reduce unwarranted } \\
\text { variations in care }\end{array}$ & $\begin{array}{l}\text { Embedded } \\
\text { care protocols } \\
\text { and clinical } \\
\text { practice } \\
\text { guidelines }\end{array}$ & $\begin{array}{l}\text { Provide guidance to } \\
\text { all members of the } \\
\text { multidisciplinary team } \\
\text { on standards for care of } \\
\text { patients with diabetes }\end{array}$ & $\begin{array}{l}\text { Adopt the American Diabetes Association } \\
\text { standards of care for adults with type II } \\
\text { diabetes mellitus and embed these care } \\
\text { standards in the EMR }\end{array}$ \\
\hline \multirow{3}{*}{$\begin{array}{l}\text { Enhance reliability } \\
\text { of care model by } \\
\text { improving provider } \\
\text { adherence to type } \\
\text { II diabetes care } \\
\text { protocols and clinical } \\
\text { practice guidelines }\end{array}$} & Checklists & $\begin{array}{l}\text { Flag patients who present } \\
\text { for care and who are due } \\
\text { for clinical interventions. }\end{array}$ & \multirow{3}{*}{$\begin{array}{l}\text { 1)Alc twice a year } \\
\text { 2) Urine microalbumin yearly } \\
\text { 3)Diabetic retina exam } \\
\text { 4)Diabetic foot exams twice a year } \\
\text { 5)Blood pressure above standard target }\end{array}$} \\
\hline & Registries & $\begin{array}{l}\text { Flag patients who are due } \\
\text { for clinical interventions } \\
\text { but who do not present } \\
\text { for care }\end{array}$ & \\
\hline & $\begin{array}{l}\text { Best practice } \\
\text { alerts }\end{array}$ & $\begin{array}{l}\text { Alert multidisciplinary } \\
\text { team members to these } \\
\text { potential gaps in care }\end{array}$ & \\
\hline \multirow[t]{4}{*}{$\begin{array}{l}\text { Reduce medication } \\
\text { errors and improve } \\
\text { medication } \\
\text { adherence in diabetes } \\
\text { care }\end{array}$} & Allergy lists & $\begin{array}{l}\text { Alert prescriber to the } \\
\text { presence of drug allergies } \\
\text { to avoid patient harm }\end{array}$ & $\begin{array}{l}\text { Prior episode of angioedema due to } \\
\text { angiotensin converting enzyme inhibitors } \\
\text { Prior episodes of drug-induced } \\
\text { pancreatitis due to dulaglutide }\end{array}$ \\
\hline & $\begin{array}{l}\text { Drug } \\
\text { interaction } \\
\text { functions }\end{array}$ & $\begin{array}{l}\text { Alert prescriber to drug } \\
\text { interactions to avoid } \\
\text { patient harm }\end{array}$ & $\begin{array}{l}\text { Potential for hypoglycemia due to co- } \\
\text { administration of sulfonylurea and azole } \\
\text { antifungal medications }\end{array}$ \\
\hline & \multirow[t]{2}{*}{$\begin{array}{l}\text { Electronic } \\
\text { prescribing }\end{array}$} & $\begin{array}{l}\text { Avoid prescription errors } \\
\text { due to communication } \\
\text { gaps between prescriber } \\
\text { and pharmacy }\end{array}$ & $\begin{array}{l}\text { Prescriptions are transmitted directly } \\
\text { to the pharmacy, avoiding transcription } \\
\text { errors and errors in interpreting } \\
\text { handwriting }\end{array}$ \\
\hline & & $\begin{array}{l}\text { Improve patient adherence } \\
\text { to prescription regimens }\end{array}$ & $\begin{array}{l}\text { Detect failure to refill prescribed } \\
\text { medications }\end{array}$ \\
\hline
\end{tabular}

Source: Elaborated by the authors.

optimizing office workflows. While health systems have been slow to adopt many of the customer-friendly electronic tools used in other sectors (such as banking, travel, and on-line retail, among others) the patient portal is an important step in that direction.

Providers and team members can use patient portals to efficiently communicate the results and interpretation of diagnostic tests, inform patients of upcoming appointments and referrals, and can answer patient questions asynchronously, without requiring that both parties be available at the same time to talk on the telephone. Furthermore, these electronic links can help remind patients of pending or overdue care interventions, such as health screenings and chronic disease management follow up, to avoid gaps in care. Active outreach can be simple and efficient when patients and providers are linked electronically (Chart 3).

\section{Among members of the care team (horizontal integration)}

In order to effectively collaborate in the efficient and reliable care of patients, members of multi-disciplinary teams must be able to easily communicate and share information about patients. Teams engage in care planning in four phases: before the office visit, during the visit, after the visit, and between visits. The EMR supports the work of the multidisciplinary care team each of these four phases. In advance of the visit, gaps in care are identified on an EMR-generated evidence-based-protocol-driven check list and 
Chart 2. Examples of Workflows Supported by a Multi-Disciplinary Team and an EMR.

\begin{tabular}{|c|c|c|}
\hline Workflow & Example & EMR Function \\
\hline \multicolumn{2}{|c|}{ Close gaps in care identified during the pre-visit planning process: } & \multirow{4}{*}{$\begin{array}{l}\text { Checklist, registries, embedded } \\
\text { clinical protocols, and standing } \\
\text { orders }\end{array}$} \\
\hline $\begin{array}{l}\text { 1) Health screening and } \\
\text { preventive care interventions }\end{array}$ & $\begin{array}{l}\text { Occult blood testing for colon } \\
\text { cancer screening, scheduling } \\
\text { mammography, administer } \\
\text { behavioral health screens (PHQ9, } \\
\text { SBIRT, GAD7, etc.) }\end{array}$ & \\
\hline $\begin{array}{l}\text { 2) Chronic disease } \\
\text { management and testing }\end{array}$ & $\begin{array}{l}\text { Point of care } \\
\text { A1C testing, scheduling diabetic } \\
\text { eye exam }\end{array}$ & \\
\hline $\begin{array}{l}\text { 3) Alert the physician of } \\
\text { needed interventions }\end{array}$ & $\begin{array}{l}\text { Blood pressure measured noted } \\
\text { to be higher than target, remove } \\
\text { shoes for diabetic foot exam }\end{array}$ & \\
\hline Medication reconciliation & $\begin{array}{l}\text { Reconcile medication list with } \\
\text { patient and family }\end{array}$ & Medication and allergy lists \\
\hline "Scribe" functions & $\begin{array}{l}\text { Document patient history, } \\
\text { physical examination, assessment, } \\
\text { diagnosis, and plan at the time of } \\
\text { the visit }\end{array}$ & $\begin{array}{l}\text { Templates, reportable fields, } \\
\text { diagnosis look-up tables }\end{array}$ \\
\hline $\begin{array}{l}\text { Reliably performing all clinical } \\
\text { interventions ordered at the visit }\end{array}$ & $\begin{array}{l}\text { Scheduling specialist consults, } \\
\text { scheduling follow up visits, } \\
\text { ordering non-routine imaging } \\
\text { studies and labs }\end{array}$ & $\begin{array}{l}\text { Team communication protocols } \\
\text { through secure messaging, routing } \\
\text { sheet, after-visit summary }\end{array}$ \\
\hline \multicolumn{3}{|c|}{ Avoiding gaps in care during the between-visit planning process: } \\
\hline $\begin{array}{l}\text { 1) Identify patients who have } \\
\text { not visited the health unit in the } \\
\text { desired timeframe }\end{array}$ & $\begin{array}{l}\text { Contact patients and engage them } \\
\text { in follow up care }\end{array}$ & $\begin{array}{l}\text { Patient registries, links to the } \\
\text { scheduling module to find patients } \\
\text { who do not have upcoming } \\
\text { appointments }\end{array}$ \\
\hline $\begin{array}{l}\text { 2) Identify patients who } \\
\text { require advanced support for chronic } \\
\text { conditions or because of frailty }\end{array}$ & $\begin{array}{l}\text { Medical and behavioral health } \\
\text { case management services, social } \\
\text { work outreach }\end{array}$ & $\begin{array}{l}\text { Patient registries, risk stratification } \\
\text { module }\end{array}$ \\
\hline $\begin{array}{l}\text { 3) Identify patients who have } \\
\text { poorly controlled disease indicators }\end{array}$ & $\begin{array}{l}\text { Identify and outreach to patients } \\
\text { with hyperglycemia, uncontrolled } \\
\text { hypertension, or who are overdue } \\
\text { for follow up on abnormal test } \\
\text { results }\end{array}$ & $\begin{array}{l}\text { Patient registries, links to lab data } \\
\text { and imaging data modules, patient- } \\
\text { generating home monitoring data }\end{array}$ \\
\hline
\end{tabular}

Source: Elaborated by the authors.

standing orders. This permits staff to offer routine required interventions to patients, allowing those interventions to be assigned to specific staff members and relieves the physician of the burden of ordering routine interventions at the time of the visit. During the visit, all team members have real-time access to the patient's medical history and other clinical information. At the end of the visit, the EMR prints a summary of care with instructions for the patient and informs staff members of needed lab tests, imaging studies, specialist consultations, and follow up visits, so that these can be arranged in a reliable way. Care planning between visits is supported by the EMR registry functions, to track patients who are overdue for preventive or disease management interventions and to guide active outreach to these patients and to engage them in care (Chart 4).

\section{Between primary care, specialists, hospitals and community providers (vertical integration)}

Transfer of responsibility for care of a patient, during transitions of care, is a time of high risk. It is estimated that $80 \%$ of serious medical errors result from miscommunication during these hand-offs ${ }^{42}$. Better bidirectional communication between primary care physicians, specialists, and 
Chart 3. Essential features of a high functioning patient portal, best communication practices for vertical integration, best practices for medication management, best practices with regard to checklists.

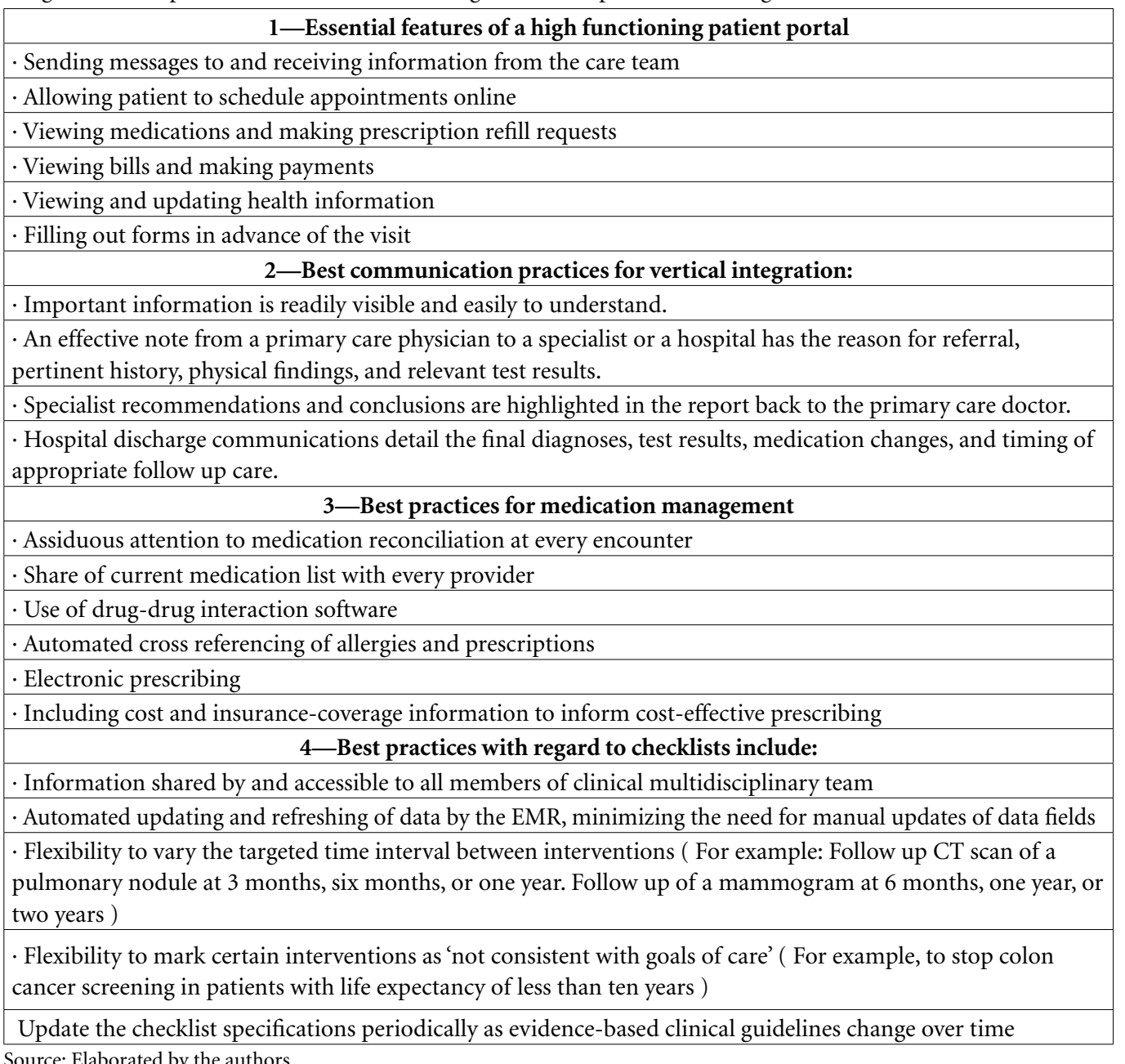

Source: Elaborated by the authors.

hospitals during times of transitions of care is supported by an EMR's secure messaging functions and by the ability of providers to seamlessly forward clinical information to one another. This is accomplished either with a common record shared by all members of an integrated care system or by using health information exchange protocols to link disparate records systems. Sharing information, communicating ideas and advice, and organizing referrals and appointments from primary care to other providers and from those providers back to primary care promotes collegiality, confidence, and collaboration between primary care and specialists (Chart 3).

Effective management of transitions of care requires more than just good communication.
It also involves coordination, standardization of work processes, training, and accountability ${ }^{43}$. Responsibilities of the referring physician and the receiving physician must be established in advance of the transfer.

\section{Medication Management within the EMR}

Medication errors represent a major threat to patient safety in ambulatory practice, contributing to an estimated 1 out of 131 outpatient deaths per year in the United States ${ }^{36}$. The electronic record offers unsurpassed tools to improve accuracy and efficiency in medication management. Medication lists can be automatically updated with each new prescription and 
Chart 4. Four Phases of Care Planning Supported by an EMR.

\begin{tabular}{|l|l|l|l|}
\hline \multicolumn{1}{|c|}{$\begin{array}{c}\text { Planning } \\
\text { Phase }\end{array}$} & \multicolumn{1}{|c|}{ EMR Function } & \multicolumn{1}{|c|}{ Workflow } & \multicolumn{1}{c|}{ Example } \\
\hline Pre-visit & Checklist & $\begin{array}{l}\text { Assign task to specific team members } \\
\text { before the patient arrives in the office }\end{array}$ & $\begin{array}{l}\text { Multidisciplinary team } \\
\text { huddles before the clinical } \\
\text { session to identify patients } \\
\text { who are overdue for } \\
\text { preventive services or } \\
\text { chronic disease management } \\
\text { interventions }\end{array}$ \\
\hline $\begin{array}{l}\text { During the } \\
\text { visit }\end{array}$ & $\begin{array}{l}\text { Checklist } \\
\text { Medication List } \\
\text { Immunization List }\end{array}$ & $\begin{array}{l}\text { Administer screening tests immunizations, } \\
\text { and chronic disease management testing } \\
\text { and treatment. Medication reconciliation }\end{array}$ & $\begin{array}{l}\text { Reliably provide necessary } \\
\text { services at the time of the } \\
\text { encounter }\end{array}$ \\
\hline $\begin{array}{l}\text { After the } \\
\text { visit }\end{array}$ & $\begin{array}{l}\text { Electronic order } \\
\text { entry } \\
\text { Referral } \\
\text { management } \\
\text { module } \\
\text { After visit summary }\end{array}$ & $\begin{array}{l}\text { Schedule specialist appointments and } \\
\text { ancillary testing. } \\
\text { Draw labs ordered at the visit. } \\
\text { Schedule follow up appointment. } \\
\text { Review prescriptions and follow up care } \\
\text { with patient. }\end{array}$ & $\begin{array}{l}\text { Reliably complete all tasks } \\
\text { ordered at the visit. } \\
\text { Assure that the patient } \\
\text { understands follow-up plan. }\end{array}$ \\
\hline $\begin{array}{l}\text { Between } \\
\text { visits }\end{array}$ & $\begin{array}{l}\text { Registries } \\
\text { Identify and contact patients who have not } \\
\text { followed up at the appropriate interval. }\end{array}$ & $\begin{array}{l}\text { Identify patients with clinical parameters } \\
\text { that are outside of established goals, i.e. } \\
\text { blood pressure or glycemic control above } \\
\text { targeted values. }\end{array}$ & $\begin{array}{l}\text { Detive outreach to those } \\
\text { in care and are not scheduled } \\
\text { for follow up. } \\
\text { patients. }\end{array}$ \\
\hline
\end{tabular}

Source: Elaborated by the authors.

rigorous attention to reconciling the medications that the patient is actually using with the medication list helps to avoid omission of essential medication or the prescription of duplicate medication. Sharing of medication lists among all providers who treat the patient helps to improve vertical integration and care coordination. Automated drug-drug interaction software helps to reduce unintentional prescriptions of drugs with adverse interactions. In some EMR systems, the cost and insurance-coverage of drugs is available to the physician at the point of care, allowing for more cost-effective choices of drugs. Very sophisticated electronic prescribing systems link prescribers and pharmacies, eliminating the need for paper prescriptions and thereby improving accuracy and efficiency in the prescribing and the drug dispensing processes (Chart 3 ).

\section{Use of EMR-generated care checklists}

An essential feature of the EMR, and one that improves the reliable delivery of services at the point of care, is the EMR-generated check list. The EMR produces a list of patient care interventions that should be provided at the visit. These interventions include vaccinations, screening procedures such as fecal occult blood tests or pap smears, mammography, depression screening, diabetes metabolic labs, follow up on abnormal imaging studies, and other interventions governed by the standards established in evidence-based care protocols. All members of the multidisciplinary team have access to this checklist. Needed interventions can be assigned to team members before the patient arrives at the office for a visit. Using standing orders, non-physician staff have the authority to obtain lab tests, schedule appointments with specialists, and perform other routine interventions

\section{Use of Registries to Guide Active Outreach to Patients with Gaps in Care}

It is always a challenge to engage some subsets of patients in appropriate follow up care. Patients commonly fail to schedule or do not keep follow up appointments and gaps in care result when patients do not present for necessary health services. Health systems are constantly trying to improve their performance on rates of cancer screening, vaccinations, and other preventive ser- 
vices, and improve their management of chronic disease (such as glycemic and blood pressure control in diabetes, follow up of abnormal test results, and adherence to the use of controller inhaler medications in asthma). The EMR offers tools, in the form of patient registries, to identify patients who do not present themselves for care but who have unmet care needs.

The registry function in many EMR systems has been slow to evolve. Flexibility in creating new registries or modifying fields and decision support rules are important functionalities. For example, being able to enter a due date for a follow up colonoscopy based on latest examination or biopsy results or being able to track and sort patient depressions screening/PHQ 9 scores to ensure appropriate outreach and follow up, can help systematize and streamline efforts to improve care.

\section{Conclusion}

There is strong evidence for the benefits of an EMR in terms of efficiency, reliability, and care quality, especially in primary care. Some of these benefits are counterbalanced by clearly defined risks and drawbacks of EMR systems. Key features of EMR systems have been identified as facilitators of or barriers to effective implementation and use of these systems to support population health, chronic disease management, the reliable delivery of preventive services, and improved patient safety through the avoidance of medical errors, especially with regard to pharmaceuticals.

Effective use of the technology requires careful attention to workflows, teamwork, and other key clinical practice reforms. The best way to take advantage of the EMR's advanced functionalities is to deploy a multidisciplinary team in a comprehensive care model. The EMR is unsurpassed as a tool to enhance communication among members of the care team and between providers at various levels of care, supporting horizontal and vertical integration. To maximize the effectiveness of the new capabilities, cultural changes at the practice and system level are necessary to support behavior norms, compacts, and mutual expectations among providers on collaboration in the care of patients.

There are many reasons why the EMR has yet to live up to its full potential and it is important to learn the lessons from past and current efforts in order to ensure the most effective design and implementation of an EMR system. Important functionalities such as modifiable check lists and registries, the ability to easily design and run reports, user friendly provider interfaces and a simple and easily accessible patient portal contribute to effective use of the EMR's complex capabilities.

The United States has seen the deployment of a variety of EMR systems with various degrees of sophistication. Considerable problems have been noted due to a lack of interoperability and standardization of interfaces among these systems, impairing the effective collaboration and information exchange in the care of complex patients. It is extremely important that regional and national health policies be established to assure standardization and interoperability of systems. Vendors of EMR systems have engaged in extensive lobbying and marketing efforts to advance the commercial and proprietary interests of their companies. These efforts contribute to the fragmentation of the information environment.

The EMR is a disruptive technology that can revolutionize the way we care for are patients. The key lessons from the US experience in the deployment and use of these systems are (1) attention to interoperability among various systems, and (2) careful attention to the impact of the EMR on clinical workflows, in order to take full advantage of the potential of the EMR to improve patient care. 


\section{Collaborations}

RS Janett and PP Yeracaris collaborated extensively in the writing of this paper and it was a true joint effort. RS Janett took primary responsibility for the evidence review, the quality section, the medication management section, and the development of the figures. PP Yeracaris took primary responsibility for the sections on team based care, facilitating communication among team members, with specialists, with patients and the use of registries to address gaps in care.

\section{References}

1. Dick RE. The Computer-Based Patient Record. Washington: National Academies Press; 1997.

2. National Coordinator for Health Information Technology (ONC). HealthIT.gov. (2017, October 5). Health IT and Health Information Exchange Basics. [cited Sept 10, 2019]. Available from: https://www. healthit.gov/topic/health-it-basics/benefits-ehrs

3. Hillestad RE, Bigelow J, Bower A, Girosi F, Meili R, Scoville R, Taylor R. Can Electronic Medical Record Systems Transform Health Care? Potential Health Benefits, Savings, and Costs. Health Affairs 2005; 24(5):1103-1117.

4. Schulte F, Frye E. Death by a Thousand Clicks. Fortune 2019; Mar 18.

5. Gorn D. These doctors think electronic records are hurting their relationships with patients. 2017, July 21. [cited Sept 10, 2019]. Available from: https://www. pbs.org/newshour/health/doctors-think-electronic-health-records-hurting-relationships-patients

6. Peikes DE. Independent Evaluation of Comprehensive Primary Care Plus (CPC+). Princeton: Mathematics Policy Research; 2019.

7. World Health Organization (WHO). WHO Framework on Integrated Person Centered Health Services. Geneva: WHO; 2019. [cited Sept 10, 2019]. Available from: https://www.who.int/servicedeliverysafety/areas/people-centred-care/en/

8. American Academy of Family Physicians, American Academy of Pediatrics, American College of Physicians, American Osteopathic Association. (2017, March). Joint Principles of the Patient Centered Medical Home. [cited Sept 10, 2019]. Available from: http:// www.aafp.org/dam/AAFP/documents/practice management/pcmh/initiatives/PCMHJoint.pdf
9. Wagner ECK. Guiding Transformation: How Medical Practices Can Become Patient Centered Medical Homes. New York: The Commonwealth Fund; 2012.

10. Holroyd-Leduc JL, Straus S, Sykes L, Quan H. The impact of the electronic medical record on structure, process, and outcomes within primary care: a systematic review of the evidence. J Am Med Inform Assoc 2011; 18(6):732-737.

11. Kemper A., Uren R, Clark S. Adoption of electronic health records in primary care pediatric practices. $\mathrm{Pe}$ diatrics 2006; 118(1):e20-24.

12. Chen C, Garrido T, Chock D, Okawa G, Liang L. The Kaiser Permanente Electronic Health Record: transforming and streamlining modalities of care. Health Aff (Millwood) 2009; 28(2):323-333.

13. Zhou Y, Garrido T, Chin H, Wiesenthal A, Liang L. Patient access to an electronic health record with secure messaging: impact on primary care utilization. Am J Manag Care 2007; 13(7):418-424.

14. Fleming N, Culler S, McCorkle R, Becker E, Ballard D. The financial and nonfinancial costs of implementing electronic health records in primary care practices. Health Aff (Millwood) 2011; 30(3):481-489.

15. Gallego A, Gagnon M, Desmartis M. Assessing the cost of electronic health records: a review of cost indicators. Telemed J E Health 2010; 16(9):963-972.

16. Pizziferri L, Kittler AF, Volk LA, Honour MM, Gupta S, Wang S, Wang T, Lippincott M, Li Q, Bates DW. Primary care physician time utilization before and after implementation of an electronic health record: a time-motion study. J Biomed Inform 2005; 38(3):176188. 
17. O’Donnell A, Kaner E, Shaw C, Haighton C. Primary care physicians' attitudes to the adoption of electronic medical records: a systematic review and evidence synthesis using the clinical adoption framework. BMC Med Inform Decis Mak 2018 13; 18(1):101.

18. Saleem JJ, Flanagan ME, Russ AL, McMullen CK, Elli L, Russell SA, Bennett KJ, Matthias MS, Rehman SU, Schwartz MD, Frankel RM. You and me and the computer makes three: variations in exam room use of the electronic health record. J Am Med Inform Assoc 2014; 21(e1):e147-151.

19. Rathert C, Mittler J, Banerjee S, McDaniel J. Patient-centered communication in the era of electronic health records: What does the evidence say? Patient Educ Couns 2017; 100(1):50-64.

20. Montague E, Asan O. Dynamic modeling of patient and physician eye gaze to understand the effects of electronic health records on doctor-patient communication and attention. Int J Med Inform 2014; 83(3):225-234.

21. Alkureishi MA, Lee WW, Lyons M, Press VG, Imam S, Nkansah-Amankra A, Werner D, Arora VM. Impact of Electronic Medical Record Use on the Patient-Doctor Relationship and Communication: A Systematic Review. J Gen Intern Med 2016; 31(5):548-560.

22. Irani JS, Middleton JL, Marfatia R, Omana ET, D’Amico F. The use of electronic health records in the exam room and patient satisfaction: a systematic review. $J$ Am Board Fam Med 2009; 22(5):553-562.

23. Shachak A, Reis $\mathrm{S}$. The impact of electronic medical records on patient-doctor communication during consultation: a narrative literature review. J Eval Clin Pract 2009; 15(4):641-649.

24. Kruse C, Stein A, Thomas H, Kaur H. The use of Electronic Health Records to Support Population Health: A Systematic Review of the Literature. J Med Syst 2018; 42(11):214.

25. Campanella P, Lovato F, Marone C, Fallacara L, Riocciardi W, Specchia $\mathrm{M}$. The impact of electronic health records on healthcare quality: a systematic review and meta-analysis. Eur J Public Health 2016; 26(1):60-64.

26. Ojeleye O, Avery A, Gupta V, Boyd M. The evidence for the effectiveness of safety alerts in electronic patient medication records systems at the point of pharmacy order entry: a systematic review. BMC Med Inform Decis Mak 2013; 13:69.

27. Gill J, Ewen E, Nsereko M. Impact of an electronic medical record on quality of care in a primary care office. Del Med J 2001; 73(5):187-194.

28. Ruffin M, Plegue M, Young A, Patel D, Yeazel M. Impact of an Electronic Health Record (EHR) Reminder on Human Papillomavirus (HPV) Vaccine Initiation and Timely Completion. J Am Board Fam Med 2015; 28(3):324-333.

29. Moody-Thomas S, Nasuti L, Yi Y, Celestin MD Jr, Horswell R, Land TG. Effect of systems change and use of electronic health records on quit rates among tobacco users in a public hospital system. Am J Public Health 2015; 105(Supl. 2:e1-7).

30. Huber M, Highland J, Krshnamoorthi V, Tang J. Utilizing the Electronic Health Record to Improve Advance Care Planning: A Systematic Review. Am J Hosp Palliat Care 2018; 35(3):532-541.
31. Cebul R, Love T, Jain A, Hebert C. Electronic health records and quality of diabetes care. $N$ Engl J Med 2011; 365(24):2338-2339.

32. Kuo A, Dang S. Secure Messaging in Electronic Health Records and its Impact on Diabetes Clinical Outcomes: A Systematic Review. Telemed J E Health 2016; 22(9):769-777.

33. Lessing SE, Hayman LL. Diabetes Care and Management Using Electronic Medical Records: A Systematic Review. J Diabetes Sci Technol 2019; 13(4):774-782.

34. Menachem N, Collum T. Benefits and drawbacks of electronic health systems. Risk Manag Healthc Policy 2011; 4:47-55.

35. Howe J, Adams K, Hettinger A, Ratwani R. Electronic Health Record Usability Issues and Potential Contribution to Patient Harm. JAMA 2018; 319(12):12761278.

36. Agency for Healthcare Research and Quality (AHRQ). Patient Safety Primer--Ambulatory Care Safety. (2019, January). [cited Sept 10, 2019]. Available from: https:// psnet.ahrq.gov/primers/primer/16/patient-safety-in-ambulatory-care

37. American College of Physicians. Patient Safety in the Office-Based Practice Setting. Philadelphia: American College of Physicians; 2017.

38. Sinsky C, Bodenheimer T. Powering-Up Primary Care Teams: Advanced Team Care with in-room support. Annals of Family Medicine; 2019.

39. Bodenheimer T. Building Powerful Primary Care Teams. Mayo Clin Proc 2019; 94(7):1135-1137.

40. Misra-Herbert A, Amah L, Rabovsky A, Morrison S, Cantave M, Hu B, Rothberg M. Medical scribes: How do their notes stack up? J Fam Pract 2016; 65(3):155159.

41. Anderson P, Halley M. A New Approach to Making Your Doctor-Nurse Team More Productive. Fam Pract Manag 2008; 15(7):35-40.

42. Solet DJ, Norvell JM, Rutan GH, Frankel RM. Lost in translation: challenge and opportunities in physician-to-physician communication during patient hand-offs. Acad Med 2005; 80(12):1094-1099.

43. The Joint Commission. (2018, January). Transitions of Care: The need for a more effective approach to continuing patient care. [cited Sept 10, 2019]. Available from: https://www.jointcommission.org/assets/1/18/ Hot_Topics_Transitions_of_Care.pdf

Article submitted on $02 / 10 / 2019$

Approved on 20/10/2019

Final version submitted on 22/10/2019 